\title{
Variation in irradiance, soil features and regeneration patterns in experimental forest canopy gaps
}

\author{
Urša Vilhar • Dušan Roženbergar • Primož Simončič • \\ Jurij Diaci
}

Received: 20 June 2014 / Accepted: 10 September 2014 / Published online: 1 October 2014

(C) The Author(s) 2014. This article is published with open access at Springerlink.com

\begin{abstract}
- Key message Natural regeneration of beech, maple and fir was investigated in relation to irradiance, ground vegetation and soil features. Seedling establishment may be favoured by creating small and irregular gaps and by successive extension of gaps along the sun-exposed gap edge.

- Context To successfully manage natural regeneration, it is important to understand the interactions of forest gap microclimates and soil features.

- Aim The aim of this study was to identify conditions for successful natural regeneration of European beech, sycamore maple and silver fir in mixed forests.
\end{abstract}

\section{Handling Editor: Erwin Dreyer}

Contribution of the co-authors Dr. Dušan Roženbergar: contribution to fieldwork, data analysis and preparation of the manuscript.

Dr. Primož Simončič: contribution to data analysis, supervision of $\mathrm{PhD}$ thesis, research project management and preparation of the manuscript. Prof. Dr. Jurij Diaci: contribution to data analysis, supervision of $\mathrm{PhD}$ thesis, research project management and preparation of the manuscript.

Electronic supplementary material The online version of this article (doi:10.1007/s13595-014-0424-y) contains supplementary material, which is available to authorized users.

U. Vilhar $(\bowtie) \cdot$ P. Simončič

Slovenian Forestry Institute, Večna Pot 2, 1000 Ljubljana, Slovenia

e-mail: ursa.vilhar@gozdis.si

P. Simončič

e-mail: primoz.simoncic@gozdis.si

D. Roženbergar $\cdot$ J. Diaci

Department of Forestry and Renewable Forest Resources,

Biotechnical Faculty, University of Ljubljana, Večna pot 83,

SI-1000 Ljubljana, Slovenia

D. Roženbergar

e-mail: dusan.rozenbergar@bf.uni-lj.si

J. Diaci

e-mail: jurij.diaci@bf.uni-lj.si
- Methods Seedling growth and survival were recorded within and around two artificial gaps, and the relationships to irradiance, ground vegetation and soil features were examined. A simple conceptual model was applied to identify optimal micro-sites for regeneration.

- Results Ground vegetation hindered the establishment of natural regeneration in the centre of the gaps. Small seedlings of maple and beech were more abundant within the small gap and along gap edges; beech had the highest density on sunexposed edges and maple on shaded gap edges. Tall beech and maple seedlings were more abundant along sun-exposed gap edges. Greater variability of irradiance in the larger gap contributed to greater micro-site heterogeneity relative to the small gap.

- Conclusions Seedling establishment may be favoured by creating small and irregular gaps and by successive extension of gaps along the sun-exposed gap edge. Circular gaps with diameters greater than stand height contribute to increased ground vegetation coverage and hinder tree regeneration, including semi-shade tolerant maple and spruce.

Keywords Gap partitioning · Natural regeneration - Abies alba $\cdot$ Fagus sylvatica $\cdot$ Acer pseudoplatanus $\cdot$ Solar radiation · Micro-site variability $\cdot$ Ground vegetation · Dinaric Alps

\section{Introduction}

Successful natural regeneration of mixed forests requires knowledge of the effects of the partitioning of micro-sites in canopy gaps on the coexistence of tree species (Gray and Spies 1996; Carlson and Groot 1997). An understanding of the interactions of the forest gap micro-climate and the soil features that define the partitioning of the gap micro-site is important for successfully managing natural tree regeneration. 
The gap size, shape, orientation and spatial dynamics (hereafter referred to as gap spatiotemporal geometry) have important effects on many ecological factors and processes in gaps. Both canopy release and gap creation induce sudden changes in solar radiation and other micro-climate variables, such as air and soil temperature, rainfall, air humidity and wind (Morecroft et al. 1998; Aussenac 2000; Proe et al. 2001). The micro-climate affects nutrient release through decomposition and mineralisation processes (Muscolo et al. 2010) and, together with water fluxes (Vilhar et al. 2010), results in the loss of nutrients from the forest ecosystem (Madsen 1994; Katzensteiner 2003; Walters et al. 2006). Micro-climatic changes (Ritter et al. 2005; Renaud and Rebetez 2009) and the undesirable loss of nutrients (Ritter and Vesterdal 2006) are less pronounced in small canopy gaps than in large areas of open space. Furthermore, the growth of regeneration and edge trees in small and irregular canopy gaps, which result in increased interception, shading (Čater et al. 2013) and water extraction by roots (Cudlin et al. 2007), may modify the gap effect as early as the second year after gap creation in semi-natural beech-dominated forests (Ritter et al. 2005).

Ecological differences among positions within gaps may be partly due to the variability of factors that do not depend on irradiation, such as micro-relief, soil substrates and woody debris (sensu Brandani et al. 1988), and could partially be affected by the north-south solar radiation asymmetry within the gaps (Takenaka 1988; Poulson and Platt 1989). In addition to the gap spatiotemporal geometry, any micro-scale heterogeneity within gaps significantly affects regeneration success (Gray and Spies 1996).

The natural regeneration of managed mixed silver fir (Abies alba Mill.; hereafter fir) and European beech (Fagus sylvatica $\mathrm{L}$.; hereafter beech) forests has been investigated in many studies (e.g. Schmidt-Vogt 1972; Matić 1983; Mosandl 1991; Stancioiu and O'Hara 2006; Klopcic and Boncina 2012). The results indicated that fir exhibits superior establishment potential at a low irradiance, followed by beech and Norway spruce (Picea abies (L.) Karst; hereafter spruce). In addition, sycamore maple (Acer pseudoplatanus L.; hereafter maple) is rated as moderately shade tolerant. Because of the prevalence of shade-tolerant species in this type of forest, natural regeneration is often induced by the creation of small, diffuse canopy openings, by their gradual formation and extension and by the favouring of advance regeneration (irregular shelterwood systems sensu Matthews 1999). Generally, this system emulates natural disturbance dynamics, which are driven by endogenous factors (Leibundgut 1982). In addition, recent studies of disturbance regimes (e.g. Nagel et al. 2013) have revealed that intermediate disturbances such as windstorms also play an important role. However, regarding managed silver fir forests, there is little information regarding the regeneration processes in medium-sized gaps, i.e. those with diameters larger than the height of the surrounding stand. Such gaps are often considered important for promoting moderately shade tolerant, commercially valuable tree species, such as maple (Kobal et al. 2013).

Knowledge of the optimal micro-site conditions for the regeneration of tree species within gaps is useful to silviculturists when developing optimal models of gap spatiotemporal geometry during regeneration (Diaci 2002; de Chantal et al. 2003). Consequently, simple conceptual models of the distribution of ecological factors within gaps may help silviculturists improve regeneration success. However, these mechanisms should be studied over long time intervals in experimental gaps with a well-documented stand history (Čater and Levanič 2013) because an inadequate time series of measurements, abundant advance regeneration and gradual gap extension may significantly affect the results.

The aim of this study was to evaluate the optimal micro-site conditions regarding the irradiance, ground vegetation and soil features on the natural regeneration patterns in two experimental canopy gaps of different sizes in a mixed forest of fir and European beech. The specific objectives were (1) to assess the variability of regeneration performance between gap positions while hypothesising larger survival and growth of the moderately shade-tolerant species in the high-light conditions, (2) to assess the ecological factors aside from irradiance that control the regeneration (e.g. ground vegetation coverage and soil water content) and (3) to apply a simple conceptual model for distinguishing four distinct micro-sites within and around gaps based on the distribution of irradiance.

\section{Methods}

\subsection{Site and stand description}

The fir-beech forests under investigation are located in south-eastern Slovenia $\left(45^{\circ} 20^{\prime} \mathrm{N}, 14^{\circ} 30^{\prime} \mathrm{E}\right.$, elevation 860-890 $\mathrm{m}$ a.s.1.) in the northern Dinaric Alps in the western Balkan Peninsula. The bedrock consists of Cretaceous limestone, and the soil depth varies from 10 to $40 \mathrm{~cm}$ depending on the highly variable karstic micro-relief. The prevailing soil units were Eutric Cambisols and Rendzic Leptosols (Urbančič et al. 2005). The climate of the region is montane with an annual precipitation of up to $1,600 \mathrm{~mm}$. The long-term (1961-1990) mean annual air temperature recorded at the nearest meteorological station (Kočevje, $45^{\circ} 39^{\prime} \mathrm{N}, 14^{\circ} 51^{\prime} \mathrm{E}, 467 \mathrm{~m}$ a.s.1.) was $8.3{ }^{\circ} \mathrm{C}$ (Supplementary data 1 ). Based on this value and on an environmental lapse rate of $6{ }^{\circ} \mathrm{C}$ per kilometre of elevation, the long-term mean annual temperature at the study site was $5.9^{\circ} \mathrm{C}$ (Vilhar et al. 2006).

The vegetation type of the stand in which the study was conducted was classified as Omphalodo-Fagetum (Puncer 
1980). The species composition, based on the stand volume in forest compartment 14 (39.32 ha) of the Črmošnjice forest management unit where the gaps were created, was $55 \%$ fir, $25 \%$ beech, $15 \%$ spruce and $5 \%$ maple (2007). Elm (Ulmus glabra Huds.) and lime (Tillia cordata Mill.) comprised less than $1 \%$ of the total volume. The total volume in the forest compartment was $255 \mathrm{~m}^{3} \mathrm{ha}^{-1}$, and the total basal area was $52 \mathrm{~m}^{2} \mathrm{ha}^{-1}$. The forest had previously been managed using the irregular shelterwood system (sensu Matthews 1999).

\subsubsection{Study forest and gaps}

In the 2000/2001 winter, two circular experimental gaps were created by way of a single cut: a medium gap (diameter of ca. $55 \mathrm{~m}$ ) and a small gap (diameter of ca. $30 \mathrm{~m}$ ). The distance between the two gap centres was $75 \mathrm{~m}$. In the small gap, the prevailing slope aspect was to the east, whereas the medium gap had a predominantly south-eastern aspect. The slope gradients in both gaps were similar, with mean gradients of $18.4^{\circ}$ in the small gap and $20.2^{\circ}$ in the medium gap. The stand was mature, with closed canopies and no advance regeneration taller than $20 \mathrm{~cm}$; the few larger seedlings present were all removed. For our study, all of the trees within the areas of the planned canopy gaps were harvested and carefully removed by horse skidding. In the spring of 2001, 113 sampling plots in the medium gap and 43 sampling plots in the small gap were set up in a grid with an internal spacing interval of $5 \times 5 \mathrm{~m}$ in the compass directions. The grid extended into the adjacent forest at the gap edges. Each sampling plot was $1.5 \times 1.5 \mathrm{~m}$.

\subsection{Woody regeneration performance}

All tree seedlings at the sampling plots were recorded based on their species and height (small seedlings with heights of up to $20 \mathrm{~cm}$ and tall seedlings with heights of more than $20 \mathrm{~cm}$ ) (sensu Ott et al. 1991), and their density was calculated as the number of individuals per meter squared. The results for the spruce seedlings were recorded only as total numbers due to their low density. For the five tallest beech seedlings in the plot, the average heights, the height increments of the terminal shoots in the final year, and the diameters above the root collars were measured.

In the summer of 2001 and 2006, browsing damage to all seedlings in the sampling plots was estimated. The visible browsing damage to the main stem and side shoots was assigned to two classes as follows: (a) undamaged seedlings, i.e. those seedlings with no or limited damage with up to $10 \%$ damaged shoots and no damage to the terminal shoot, and (b) damaged seedlings, i.e. those with more than $10 \%$ damaged shoots and/or terminal shoot damage.

\subsection{Variability of ecological factors}

\subsubsection{Irradiance}

In the summer of 2003, the irradiance parameters in each sampling plot were assessed using digital hemispherical photos that were taken at an elevation of $0.8 \mathrm{~m}$ above the ground during completely overcast sky conditions near dawn or dusk to avoid direct radiation (Roženbergar et al. 2011). A Nikon Coolpix 995 digital camera equipped with a calibrated fisheye lens from Regent WinScanopy was used. Pixel classification was performed automatically using the blue colour channel in the SideLook 1.1 software (Nobis and Hunziker 2005). Next, the irradiance parameters were processed using the WinScanopy 2003 pro-b software (Regent 2003). For further analysis, the indirect site factor (ISF), which is defined as the relative proportion of the diffuse components of the radiation fluxes at the measuring point to the diffuse components in the open area conditions, and the direct site factor (DSF), which is defined as the relative proportion of the direct component of the radiation fluxes at the measuring point to the direct component in the open area conditions, were selected (Fig. 1).

\subsubsection{Ground vegetation coverage}

Stands were relatively dense before the creation of gaps; therefore, only some advance regeneration was removed. After the gap creation in the summer of 2001 and again in the summer of 2006, we recorded the coverage (\%) of all vascular plants in each sampling plot (VEGE). In each sampling plot, the site indices of irradiance, soil moisture, $\mathrm{pH}$ and soil nitrogen content were assessed using the phyto-indicator methods that were developed by Ellenberg et al. (1992).

\subsubsection{Soil properties and soil water content}

The thicknesses of the Of and Oh horizons (O), A horizon (A), $\mathrm{B}$ and $\mathrm{E}$ horizons $(\mathrm{B}+\mathrm{E})$, the total thicknesses of the mineral part of the soil (M, which is the sum of A, B and E) and the percentage of gravel ( $>2 \mathrm{~mm}$ ) were assessed in each sampling plot in 2004. The water content of the topsoil was measured monthly in all of the plots during the 2003 and 2004 growing seasons using time domain reflectometry (TDR; Prenart equipment $\mathrm{ApS}$ ) with probes that were extended to a depth of $10 \mathrm{~cm}$ (Vilhar 2006). For further analysis, the minimum (SM MIN), maximum (SM MAX) and average (SM AVG) topsoil moisture contents during the measuring period were used. In addition, topographical variables, including the slope aspect, slope gradient, coverage of rocks (ROCK) and 


\section{a}

\section{Medium gap}

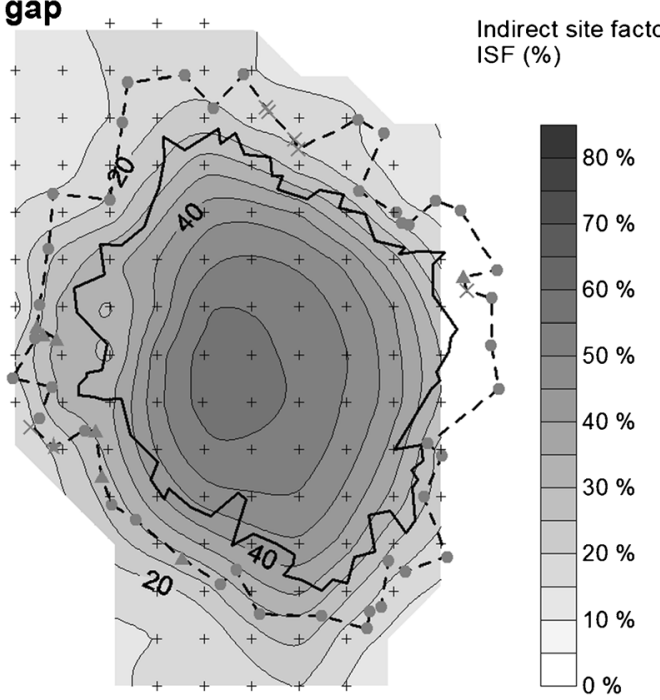

\section{b}

\section{Medium gap}

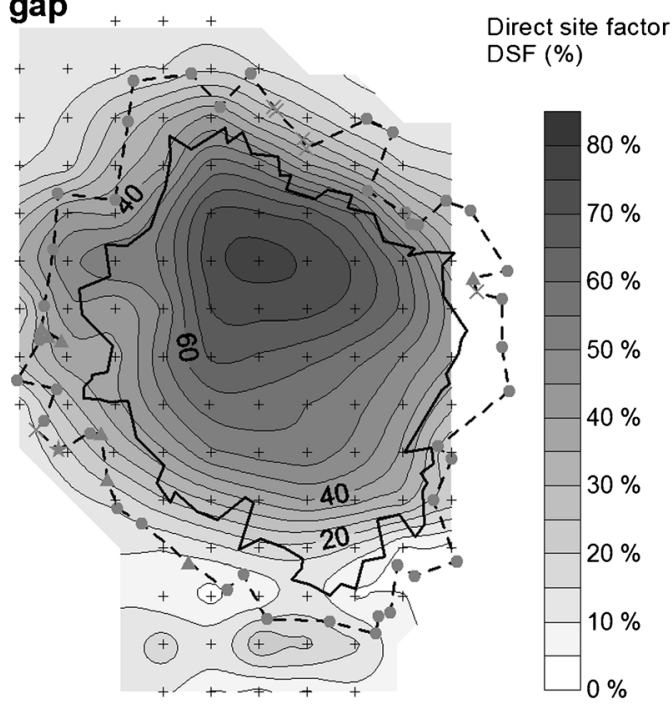

Direct site factor DSF (\%)

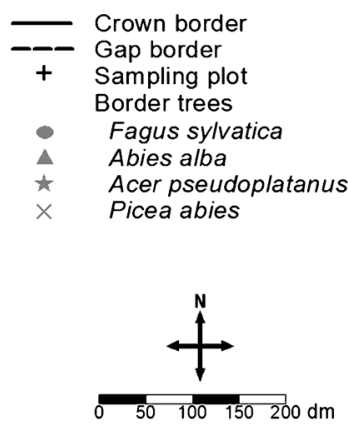

\section{Small gap}

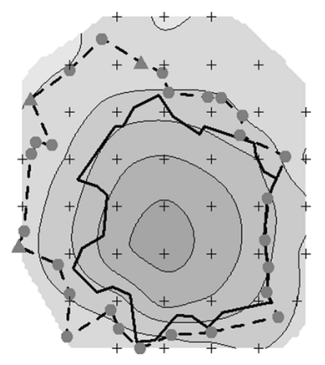

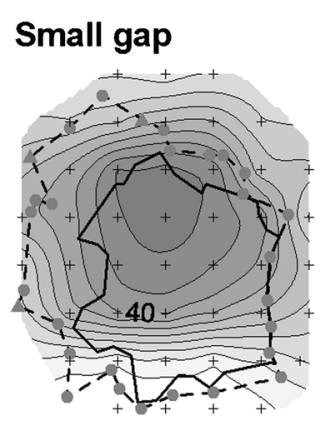

Fig. 1 a Indirect site factor (ISF \%) and $\mathbf{b}$ direct (DSF \%) site factor values for the sampling plots in the medium gap ( $n=113)$ and in the small gap ( $n=43$ )

proportion of gravel (GRAVEL) in the soil stratum, were estimated in each sampling plot (to the nearest $10 \%$ ).

\subsection{A conceptual model for distinguishing micro-sites}

To distinguish optimal micro-site conditions for woody regeneration within and around gaps, all of the sampling plots in the gaps were assigned to four classes of gap positions (A, B, C and D) based on their direct and indirect site factors (DSF and ISF). This method was developed by Diaci (2002) based on the variable ecophysiological responses of tree seedlings in four gap positions (Čater et al. 2014) and has been found to successfully facilitate the transfer of results to silvicultural practice (ibid.). Due to the non-normal distribution, the following median values of the DSF and ISF were used as thresholds: for $\mathrm{M}_{\mathrm{DSF}}$ was $31.2 \%$, for $\mathrm{M}_{\mathrm{ISF} 1}$ was $17.5 \%$ and for $\mathrm{M}_{\mathrm{ISF} 2}$ was $33.7 \%$ (Fig. 2). Consequently, 39 plots located along the gap edges with high ISFs and low DSFs were assigned to a gap edge with less sun exposure (gap position A). In addition, 38 plots in the gap centres with the highest irradiance, which corresponded to the highest ISFs and DSFs, were assigned to the gap centre (gap position B). Furthermore, 40 plots under the forest canopy with the lowest ISFs and DSFs were assigned to gap position C. Finally, 38 plots along the edges of the gaps, which corresponded to low ISFs and high DSFs, were assigned to the sun-exposed gap edge (gap position D) (Fig. 3).

\subsection{Statistical analyses}

The response of woody regeneration (density of seedlings, average height, height increment of the terminal shoot in the final year and diameter above the root collar of the five tallest beech seedlings) to selected ecological factors (Table 1) was assessed using the Kruskal-Wallis test. All of the plots (113 plots in the medium gap and 43 plots in the small gap) were grouped based on their gap positions (A, B, C and D). A post hoc comparison of the forest gaps and the plots grouped in terms of their gap positions was assessed using Nemenyi and Dunn post hoc tests (Zar 1999). Statistical data analysis was performed using the program Statistica for Windows 10.0 (2011). 


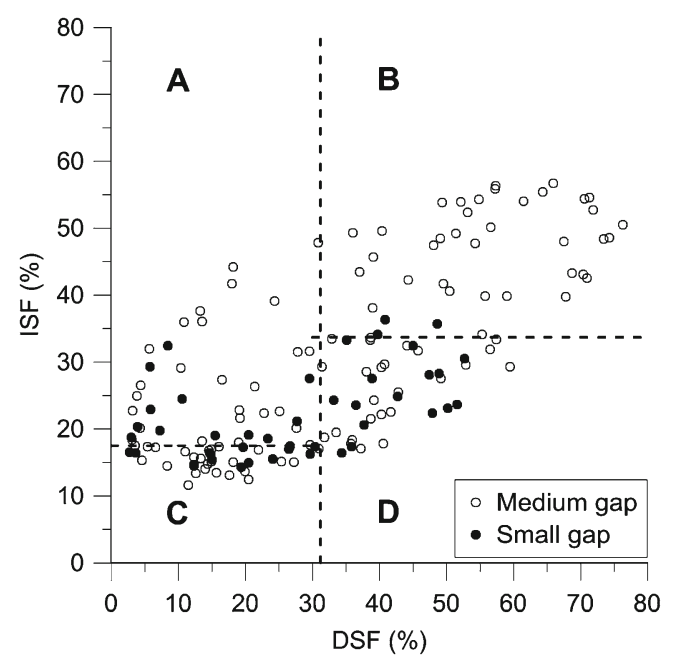

Fig. 2 Distribution of sampling plots $(n=156)$ in the medium gap and the small gap based on the indirect (ISF \%) and direct (DSF \%) site factor values. The dashed lines denote the median values of DSF and ISF that were used as thresholds for the assignment of the plots to four gap positions $(A, B, C$ and $D): M_{\mathrm{DSF}}=31.2 \%, M_{\mathrm{ISF} 1}=17.5 \%, M_{\mathrm{ISF} 2}=33.7 \%$

\section{Results}

\subsection{Woody regeneration performance}

One year after the creation of the gaps in 2001, the average density of all seedlings in the gaps amounted to 2.2 individuals per meter squared. The woody regeneration measured in the spring of 2001 reflects similar pre-harvesting histories of the gaps that were created in the former closed canopy stand and could not reflect the effect of the gap creation itself. The majority of the seedlings emerged after 2004, and by 2006, the average density had increased to 5.4 individuals per meter squared. In 2001, the maple displayed the highest density of all seedlings, at 3.8 individuals per meter squared (78 \%), followed by beech at 0.7 individuals per meter squared (15\%) and fir at 0.4 individuals per meter squared $(7 \%)$. There were only 16 individuals of beech and one maple among the tall seedlings $(0.2 \mathrm{~m}<\mathrm{h}<0.5 \mathrm{~m})$, whereas none of the regenerated seedlings was taller than $0.5 \mathrm{~m}$. During the next five growing seasons, the densities of all maple, beech and fir increased to 6.0, 3.5 and 2.8 individuals per meter squared, respectively, which correspond to 49,29 and $23 \%$ of all seedlings, respectively. Spruce regeneration was first observed in the spring of 2004 (0.1 individuals per $\mathrm{m}^{2}$ ). The most successful species in terms of recruitment from small to tall seedlings was beech, which comprised an $80 \%$ share of the tall seedlings and an increasing density over time (2004 versus 2006). In contrast, the share of maple among the tall seedlings in 2006 amounted to only $20 \%$. In 2006, we observed only one tall fir seedling in the experimental gaps.

The densities of maple and beech were higher in the small gap than in the medium gap in all observation years (Fig. 4, Supplementary data 2). In the small gap, we observed larger
Medium gap

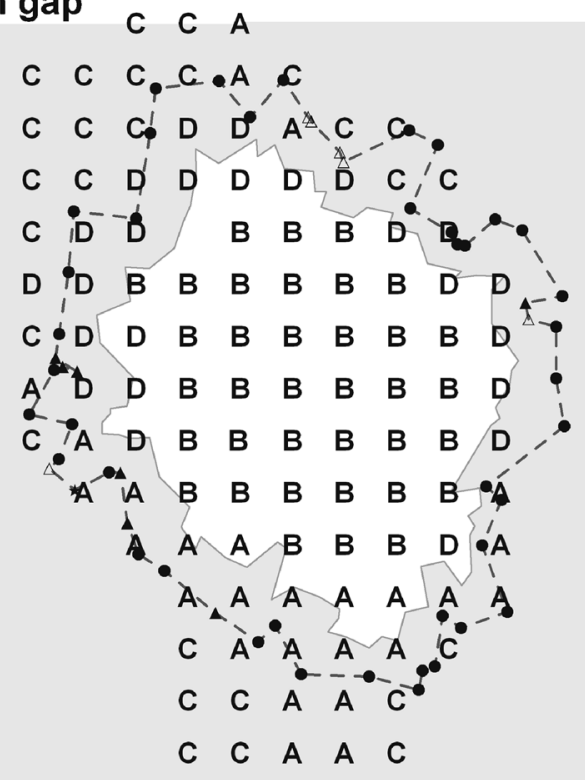

Small gap
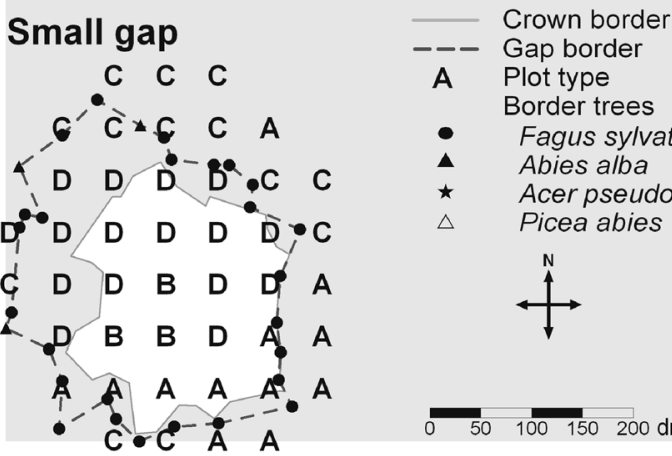

A - Gap border Border trees - Fagus sylvatica - Abies alba * Acerpseudoplatanus $\triangle \quad$ Picea abies

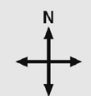

Fig. 3 Assignment of research plots to four gap positions based on direct (DSF \%) and indirect (ISF \%) site factors in the medium gap and the small gap: gap position $A$-plots located along the gap edges with less sun exposure; gap position $B$-plots in the gap centres with the highest irradiance; gap position $C$-plots under the forest canopy, which correspond to the lowest ISFs and DSFs; gap position $D$-plots along the sunexposed edges of the gaps. The median values of DSF and ISF were used as thresholds: $M_{\mathrm{DSF}}=31.2 \%, M_{\mathrm{ISF} 1}=17.5 \%, M_{\mathrm{ISF} 2}=33.7 \%$

increases from 2001 to 2006 in the small beech seedling density (i.e. 0.7 to 5.1 individuals per $\mathrm{m}^{2} ; H=25.7$, $p<0.001$ ) and the small maple seedling density (i.e. 8.0 to 12.9 individuals per $\mathrm{m}^{2} ; H=31.7, p<0.001$ ). The fir density was low in both gaps during all years of the study; therefore, there were no significant differences recorded between the fir densities in the medium and small gaps. For the small fir seedling densities, significant differences were only shown in 2001 between the four gap positions $(H=8.6, p=0.035)$ (Fig. 5, Supplementary data 3). Small fir seedling densities were the highest along the sun-exposed gap edges (0.6 individuals per $\mathrm{m}^{2}$, gap position $\mathrm{D}$ ) and the lowest along the gap edges with less sun exposure $\left(0.1\right.$ individuals per $\mathrm{m}^{2}$, gap position A). Small beech seedling densities were highest under the forest canopy (1.3 individuals per $\mathrm{m}^{2}$, gap position 
Table 1 Variables and their abbreviations used in the analysis

\begin{tabular}{llc}
\hline Variable & Description & Unit \\
\hline DSF & Direct site factor & $\%$ \\
ISF & Indirect site factor & $\%$ \\
ROCK & Surface covered by rocks & $\%$ \\
GRAVEL & Gravel content & $\%$ \\
O & Thickness of Of and Oh horizons & $\mathrm{cm}$ \\
A & Depth of A horizon & $\mathrm{cm}$ \\
B + E & Depth of B and E horizons & $\mathrm{cm}$ \\
M & Depth of mineral part of soil (sum of A and & $\mathrm{cm}$ \\
VEGE & Bround vegetation cover & $\%$ \\
SM MAX & Maximal soil water content in years 2003 and 2004 & vol\% \\
SM MIN & Minimal soil water content in years 2003 and 2004 & vol\% \\
SM AVG & Average soil water content in years 2003 and 2004 & vol\% \\
\hline
\end{tabular}

C) and lowest in the central parts of the gaps (0.2 individuals per $\mathrm{m}^{2}$, gap position B). In 2001, the tall beech seedling densities were highest along the gap edges with less sun exposure ( 0.2 individuals per $\mathrm{m}^{2}$, gap position $\left.\mathrm{A}\right)$ and lowest under the forest canopy $\left(0.1\right.$ individuals per $\mathrm{m}^{2}$, gap position C). The small maple seedling densities were highest along the gap edges with less sun exposure (6.1 individuals per $\mathrm{m}^{2}$, gap position A) and lowest in the central portions of the gaps (1.6 individuals per $\mathrm{m}^{2}$, gap position $\mathrm{B}$ ).

In 2006, the small fir seedling density was the highest along the sun-exposed gap edges (3.2 individuals per $\mathrm{m}^{2}$, gap position $\mathrm{D}$ ) and was the lowest in the central parts of the gaps (1.6 individuals per $\mathrm{m}^{2}$, gap position $\mathrm{B} ; H=9.4, p=0.024$ ). The small beech seedling densities remained the highest under the forest canopy (5.0 individuals per $\mathrm{m}^{2}$, gap position $\mathrm{C}$ ) and the lowest in the central parts of the gaps ( 0.3 individuals per $\mathrm{m}^{2}$, gap position $\mathrm{B} ; H=36.5, p<0.001$ ). The tall beech seedling densities in 2006 were the highest along the sun-exposed gap edges ( 1.2 individuals per $\mathrm{m}^{2}$, gap position $\left.\mathrm{D}\right)$ and remained the lowest under the forest canopy ( 0.2 individuals per $\mathrm{m}^{2}$, gap position $C ; H=20.9, p<0.001)$. In addition, the small maple seedling density in 2006 remained the highest along the gap edges with less sun exposure (10.4 individuals per $\mathrm{m}^{2}$, gap position A) and lowest in the central parts of the gaps (1.7 individuals per $\mathrm{m}^{2}$, gap position $\mathrm{B} ; H=17.4, p=0.001$ ), similar to 2001. The increases in the densities of the beech, maple and fir tall seedlings from 2001 to 2006 were lowest in the central parts of the gaps ( 0.2 individuals per $\mathrm{m}^{2}$, gap position $\mathrm{B}$ ).

In 2004 and 2006, the diameters, heights and height increments of the five dominant beech seedlings in each plot were lowest under the forest canopy (gap position $\mathrm{C}$ ) and significantly greater in the central parts of the gaps (gap position B) with the largest irradiance (Fig. 1) and soil water availability (Supplementary data 4) $(p \leq 0.003)$. From 2001 to 2006, the greatest increases in the diameters and height increments of the five dominant beech seedlings were observed along the sun-exposed gap edges (gap position D) $(p<0.001)$.

There were no significant differences between the degrees of browsing damage among the gaps or gap positions. The total proportion of browsed regeneration decreased substantially during the 5 -year period, from 64 to $18 \%$ damaged seedlings per plot. The decrease in damage was most noticeable among the beech seedlings, which declined from $81 \%$ in 2001 to $6 \%$ in 2006. During the same period, the proportion of damaged fir and maple seedlings decreased from 17 to $4 \%$ and from 65 to $27 \%$ per plot, respectively.

\subsection{Variability of ecological factors}

\subsubsection{Irradiance}

The irradiance differed significantly between the gaps (for ISF $p=0.005$ ). Lower values of the direct (DSF) and diffuse site factors (ISF) were observed in the small gap (Fig. 6, Supplementary data 2) and under the forest canopy (gap positions A and C) (Fig. 7, Supplementary data 3). The variability in the irradiance was significantly higher in the medium gap (interquartile range of $36 \% \mathrm{DSF} / 25 \% \mathrm{ISF}$ ) than in the small gap ( $25 \% \mathrm{DSF} / 11 \% \mathrm{ISF})$; thus, there was a higher potential for micro-site partitioning in the medium gap (Figs. 2 and 3).

\subsubsection{Ground vegetation coverage}

In 2001, specifically during the first growing season after the gap formation, there was no significant difference between the ground vegetation coverage in the two gaps, which was $6.2 \%$ in the small gap and $5.5 \%$ in the medium gap. In addition, there was no significant difference in the ground vegetation coverage between the gap positions in 2001. This trend anticipates similar pre-harvesting histories of both gaps that were created in the formerly closed canopy stand.

In the autumn of 2004 and 2006, the ground vegetation coverage markedly increased in both gaps, but the differences among the gaps were not statistically significant $(p>0.05)$. The increase in the ground vegetation coverage was greater in the small gap (from $35.9 \%$ in 2004 to $44.9 \%$ in 2006) than in the medium gap (from $51.8 \%$ in 2004 to $55.7 \%$ in 2006). The ground vegetation coverage was significantly greater in the central parts of the gaps $(87.4 \%$ in 2004 and $82.5 \%$ in 2006, gap position B) and lowest under the forest canopy (21.9\% in 2004 and $22.5 \%$ in 2006, gap position $C)(p<0.001)$.

In 2001, the three plant species that displayed the highest mean rates of coverage were Dryopteris filix-mas $(2.0 \%)$, Lamium orvala $(1.8 \%)$ and Polystichum aculeatum $(1.5 \%)$ in the medium gap and Salvia glutinosa $(1.7 \%)$, L. orvala 
2001

Fagus sylvatica

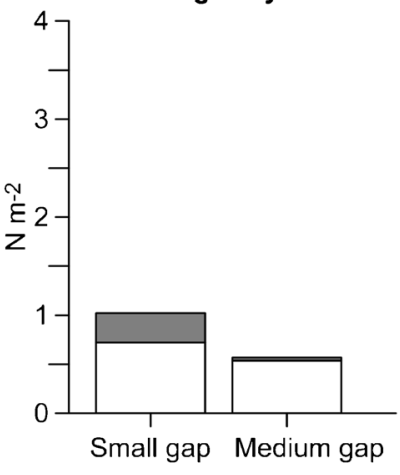

2003

Fagus sylvatica

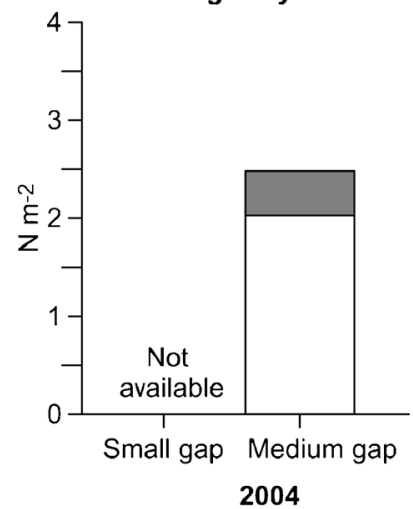

Fagus sylvatica

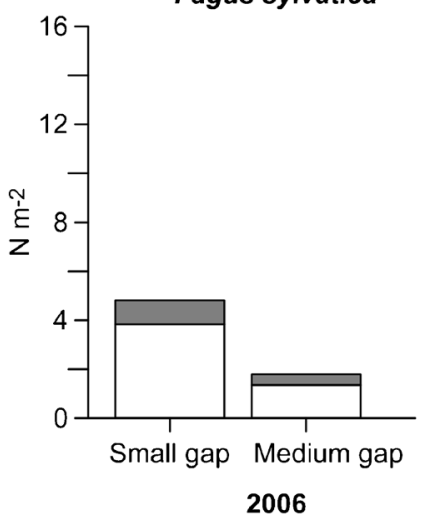

Fagus sylvatica

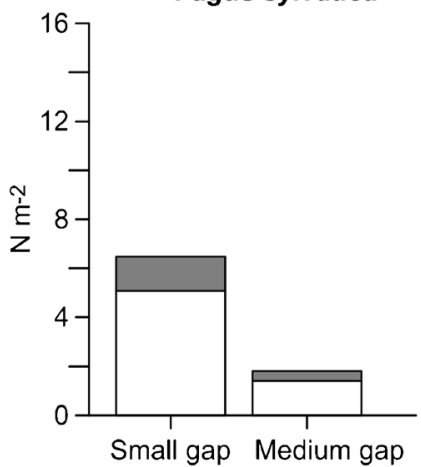

2001

Abies alba

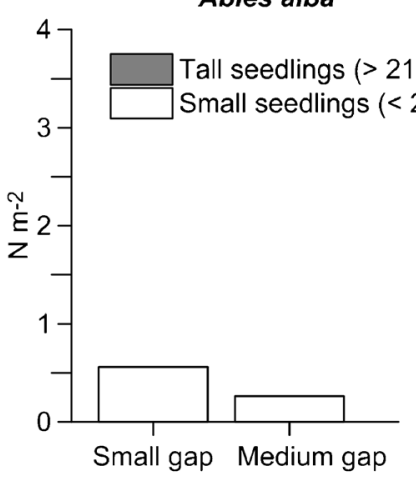

2003

Abies alba

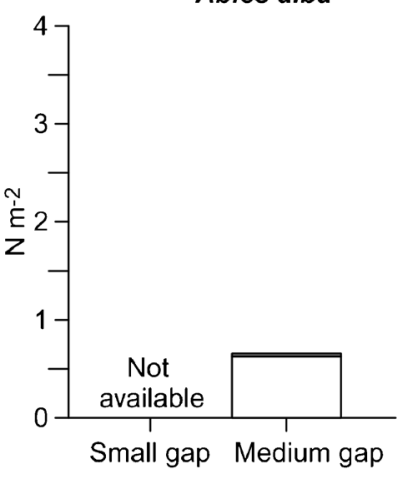

2004

Abies alba

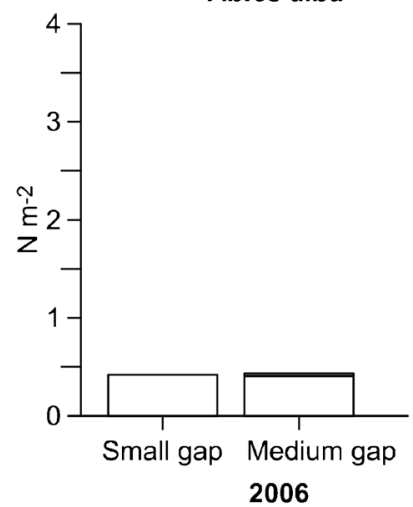

Abies alba

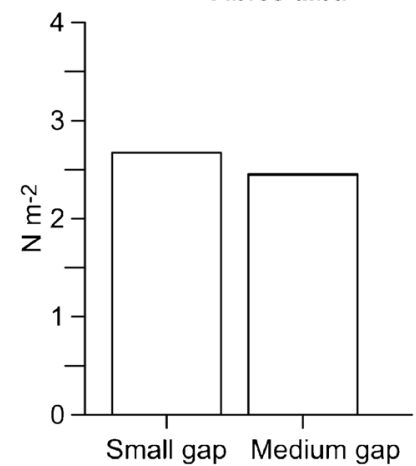

2001

Acer pseudoplatanus

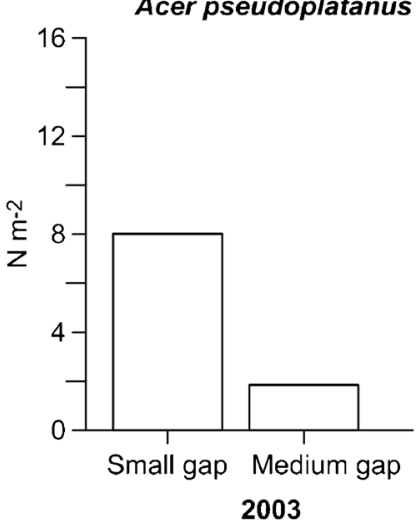

Acer pseudoplatanus
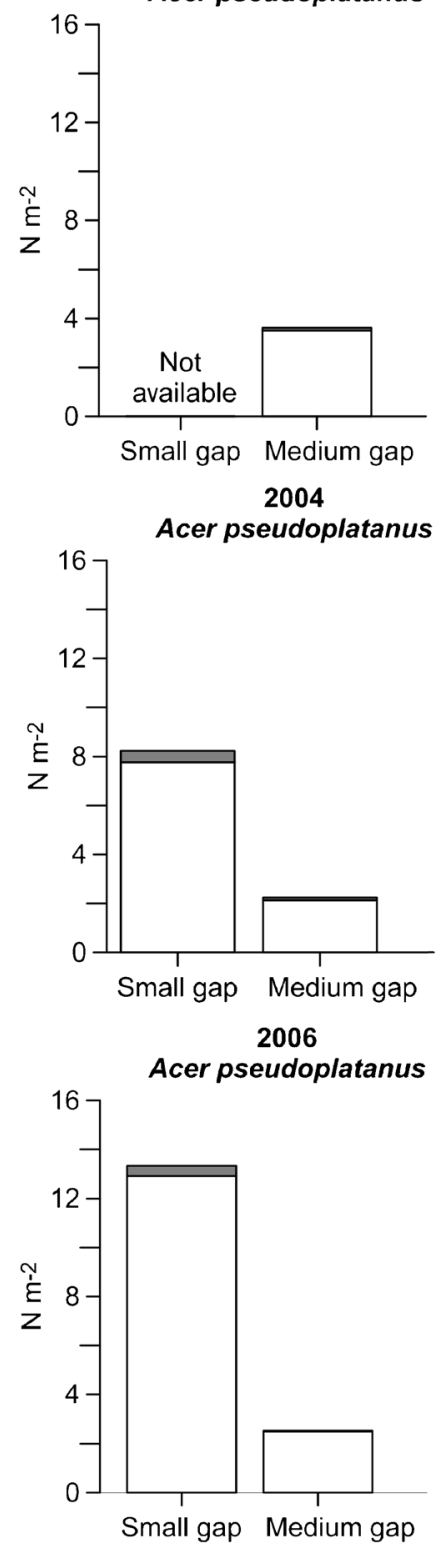

Fig. 4 Density of seedlings up to $20 \mathrm{~cm}$ tall and taller than $20 \mathrm{~cm}$ in the medium gap and small gap during the years 2001, 2003, 2004 and 2006. Please note the different scales for the different species. Not available refers to missing data 
2001

Fagus sylvatica

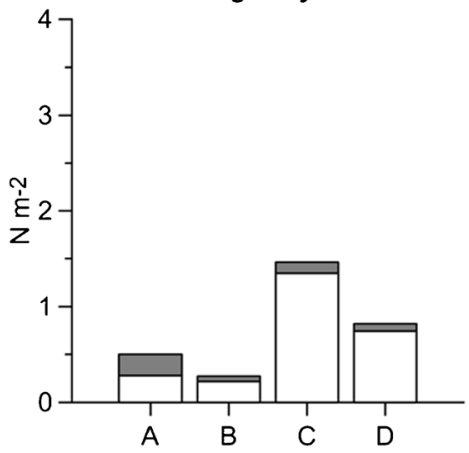

2003

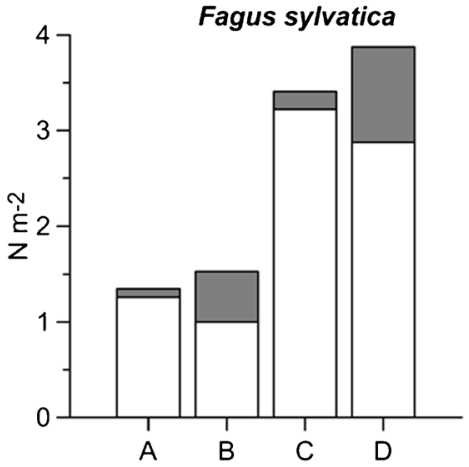

2004

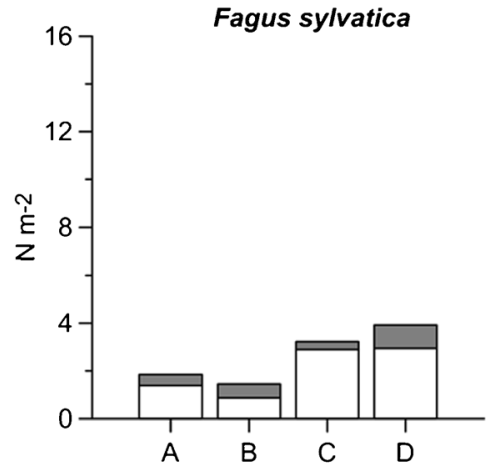

2006

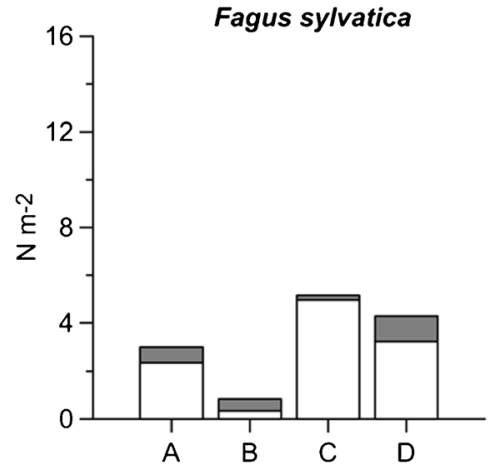

2001

Abies alba

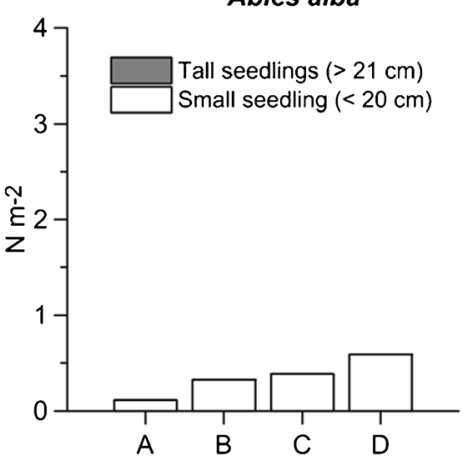

2003

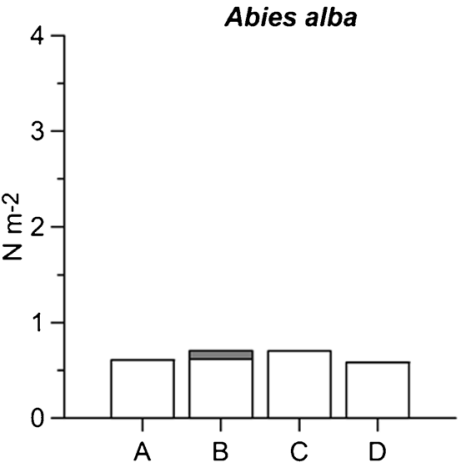

2004

Abies alba

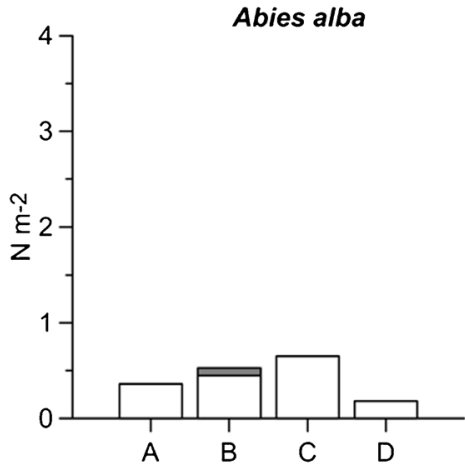

2006

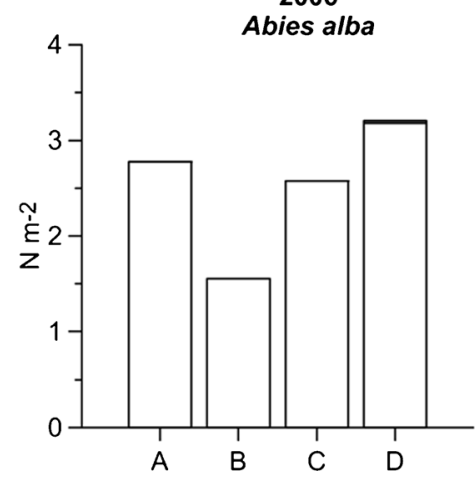

2001

Acer pseudoplatanus

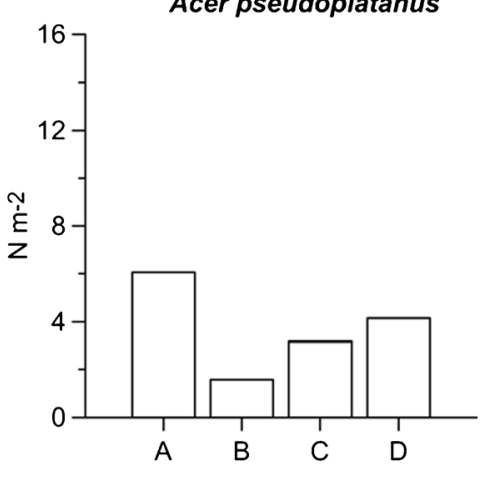

2003

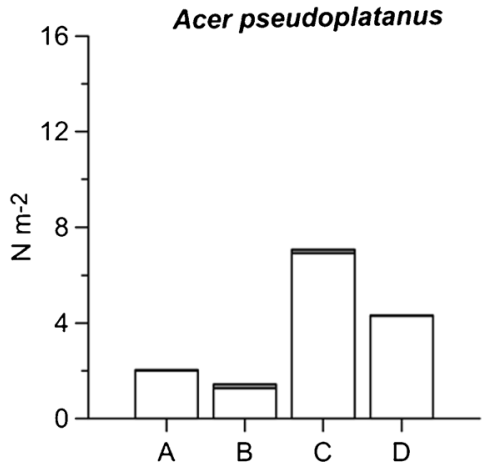

2004

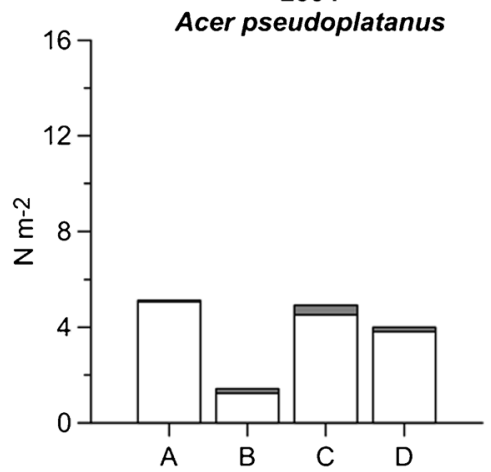

2006

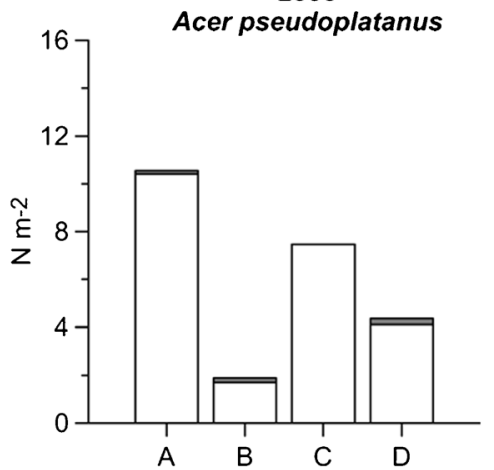

Fig. 5 Density of small seedlings (heights up to $20 \mathrm{~cm}$ ) and tall seedlings (taller than $20 \mathrm{~cm}$ ) in the medium gap and small gap based on four withingap positions ( $A, B, C$ and $D$ ) during the years 2001, 2003, 2004 and 2006: gap position $A$ - plots located along the gap edges with less sun exposure; gap position $B$ - plots in the gap centres with the highest

irradiance; gap position $C$ - plots under the forest canopy, which correspond to the lowest ISFs and DSFs; gap position $D$ - plots along the sunexposed edges of the gaps. Please note the different scales for the different species 


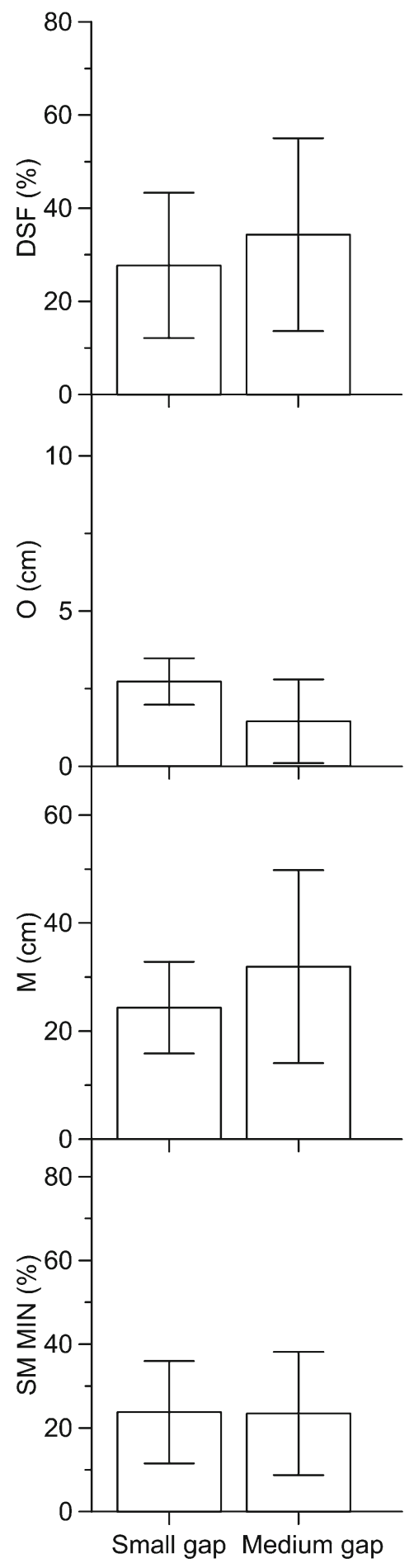

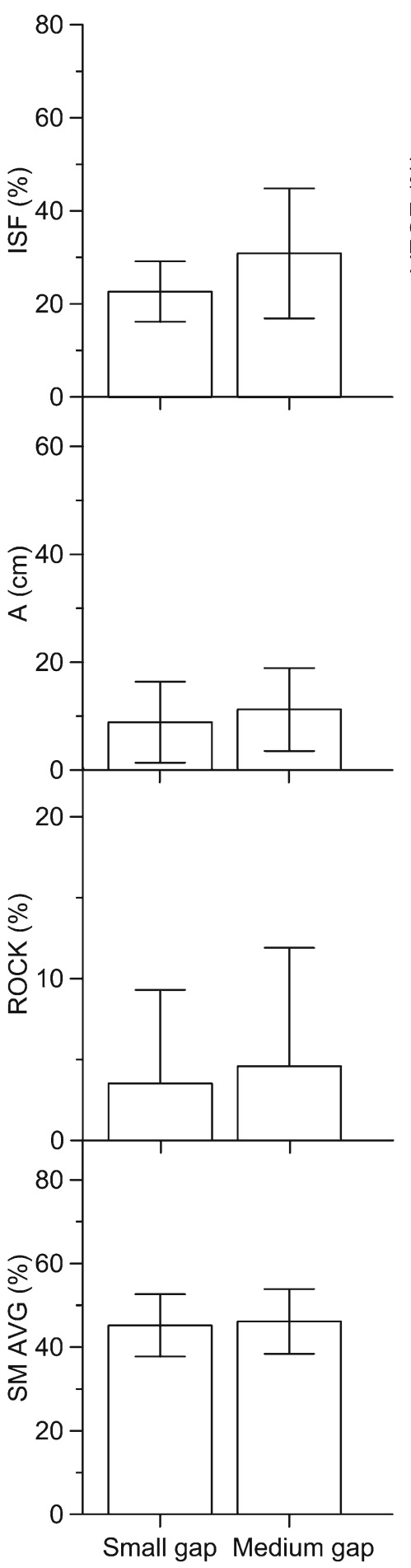

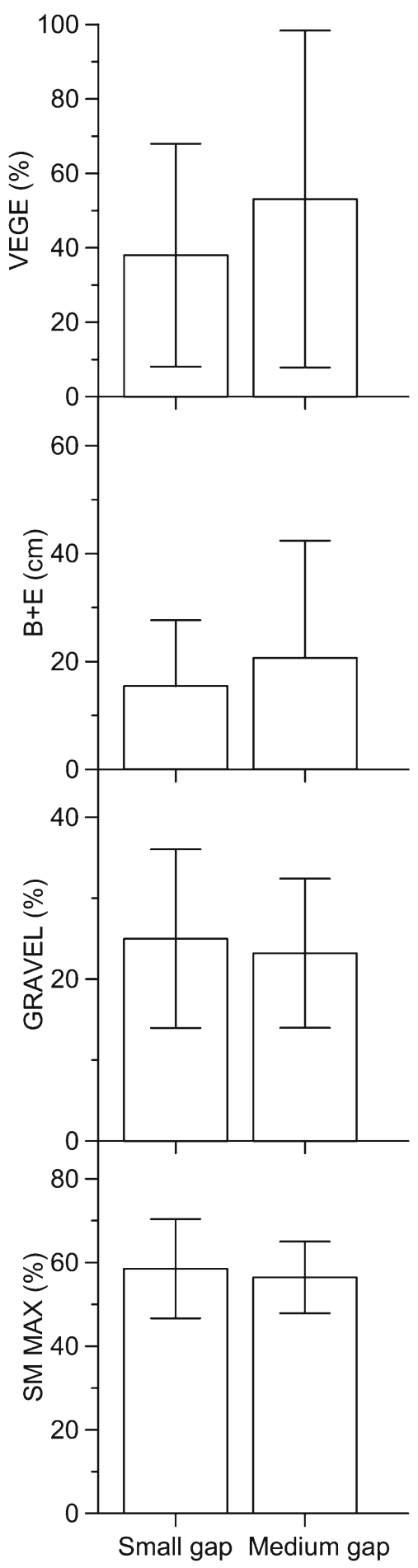

Fig. 6 Mean values and standard deviations of variables in the medium gap and the small gap for the year 2004: DSF direct site factor (\%), ISF indirect site factor (\%), ROCK surface covered by rocks (\%), GRAVEL gravel content (\%), $O$ thickness of $O$ and $O h$ horizons (cm), $A$ depth of A horizon $(\mathrm{cm}), B+E$ depth of $\mathrm{B}$ and $\mathrm{E}$ horizons $(\mathrm{cm}), M$ depth of mineral

$(1.2 \%)$ and Senecio fuchsii (1.2\%) in the small gap. The species compositions of the plants with the highest mean coverage changed markedly during the 5 -year period. The most common plant species in 2006 were Carex pendula part of soil (sum of A and B + E horizons) $(\mathrm{cm}), V E G E$ ground vegetation cover (\%), SM MAX maximum soil water content in 2003 and 2004 (\%), SM MIN minimum soil water content in 2003 and 2004 (vol\%), SM AVG average soil water content in 2003 and 2004 (vol\%)

(29.0\%), Fragaria vesca (22.7 \%) and Carex sylvatica $(19.7 \%)$ in the medium gap and Atropa belladonna (29.0 \%), Brachypodium sylvaticum (15.2\%) and Fragaria vesca $(27.8 \%)$ in the small gap. Although the most abundant 

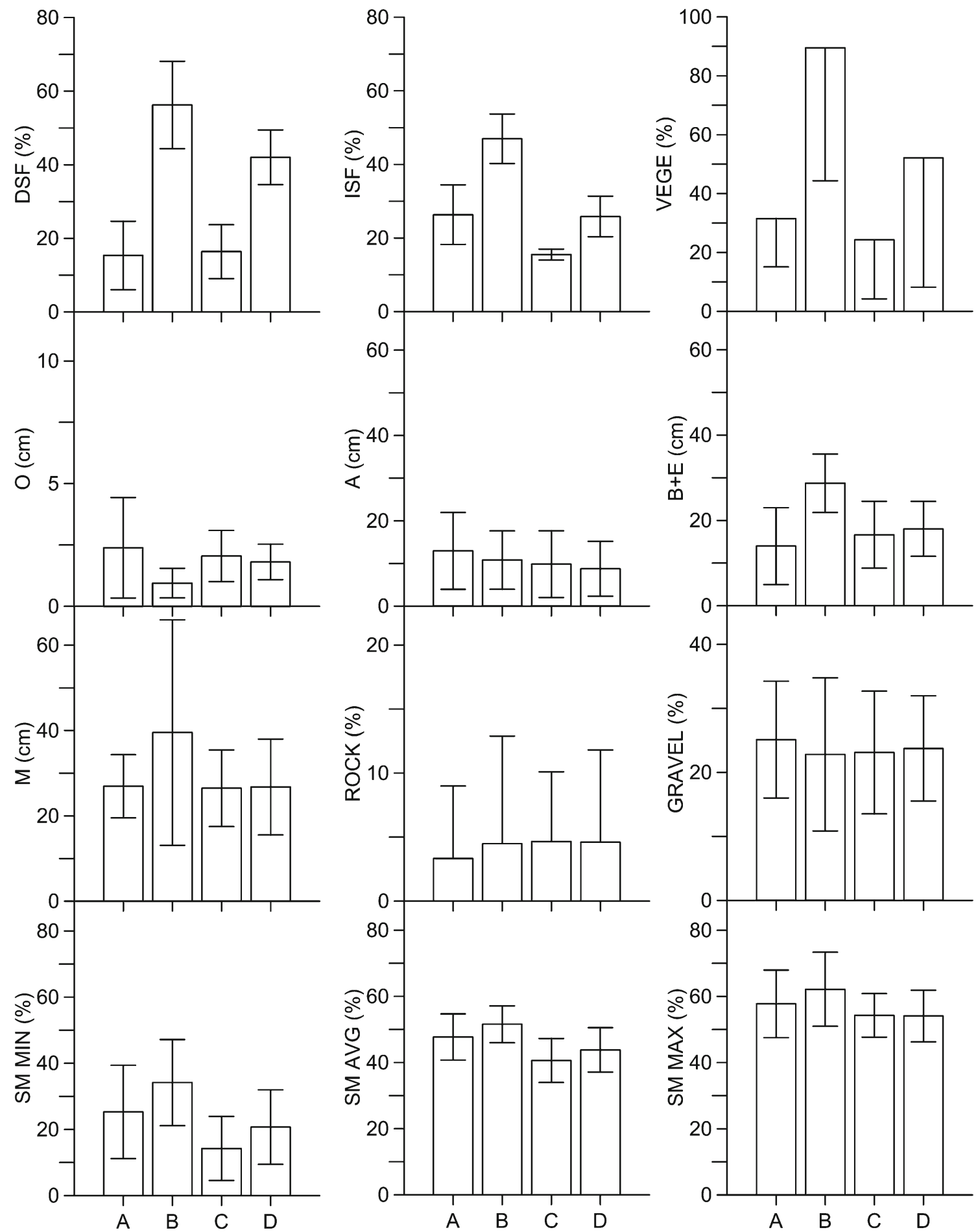

Fig. 7 Mean values and standard deviation of variables per gap position ( $A, B, C$ and $D$ ) for the year 2004: gap position $A$ - plots located along the by rocks (\%), GRAVEL gravel content (\%), $O$ thickness of $\mathrm{Of}$ and $\mathrm{Oh}$ horizons (cm), $A$ depth of A horizon (cm), $B+E$ depth of B and $\mathrm{E}$ horizons (cm), $M$ depth of mineral component of soil (sum of A and B $+\mathrm{E}$ horizons) (cm), VEGE ground vegetation cover (\%), SM MAX maximum soil water content in 2003 and 2004 (\%), SM MIN minimum soil water content in 2003 and 2004 (vol\%), SM AVG average soil water content in 2003 and $2004(\mathrm{vol} \%)$

along the sun-exposed edges of the gaps. Variable descriptions: $D S F$ direct site factor $(\%), I S F$ indirect site factor $(\%), R O C K$ surface covered

indices of irradiance and soil moisture, $\mathrm{pH}$ and soil nitrogen content based on the phyto-indicator methods (Ellenberg et al. no significant differences were observed in terms of the site 
1992). However, we recorded an increase in irradiance (from 4.0 to 4.3 ) and a decrease in the soil nitrogen content in the soil indication (from 7 to 5) from 2001 to 2006. The plant species with the highest coverage (the three species dominating each gap position) in 2006 were as follows: B. sylvaticum, Athyrium filix-femina and Fragaria vesca along the gap edges with less sun exposure (gap position A); C. pendula, C. sylvatica and Athyrium filix-femina in the central parts of the gaps (gap position B); B. sylvaticum, Galium odoratum and Salvia glutinosa under the forest canopy (gap position C); and B. sylvaticum, C. pendula and C. sylvatica along the sunexposed gap edges (gap position D). The phyto-indicators recorded in the four gap positions revealed differences in of the irradiance, soil moisture and soil nitrogen contents. In general, the differences in the recorded phyto-indicators were consistent with our measurements, but not in every detail. For example, based on the phyto-indication classification, the gap edges with less sun exposure (gap position A) were the least humid micro-sites. However, these areas were ranked as the second most humid areas based on the soil water content measurements.

\subsubsection{Soil properties and soil water contents}

The thicknesses of the $\mathrm{Ol}$ and Of horizons $(\mathrm{O})$ were significantly greater in the small gap, along the gap edges with less sun exposure (gap position A) and under the forest canopy (gap position C) $(p<0.001)$ (Supplementary data 2, 3 and 5). The thicknesses of the A horizons $(p=0.023)$ and the mineral soil layers (M) $(p=0.015)$ were significantly greater in the medium gap. The topsoil water content was more strongly influenced by the position within the gaps (Supplementary data 3) than by the size of the gaps. The size of the gaps did not correspond to significant differences in the minimum (SM MIN) and maximum (SM MAX) soil water contents (Supplementary data 4). The lowest soil water contents were measured under the closed canopy (gap position C), followed by the gap edges (gap positions $\mathrm{D}$ and $\mathrm{A}$ ), whereas the highest soil water contents were measured in the central parts of the gaps (gap position B) $(p<0.001)$. There were no significant differences among the gaps or gap positions in terms of the coverage of rocks (ROCK) or the share of gravel (GRAVEL) in the soil stratum (Supplementary data 6).

\section{Discussion}

The results of this study suggest that natural regeneration patterns in selected gaps may be induced by variations in irradiance, ground vegetation and soil features within and among gaps. Although this study involved only one small gap and one medium gap and is therefore limited by the lack of gap replication, the differentiation within and around gaps by the use of several plots does allow for an assessment of the interactions among micro-climate and soil features and the success of natural regeneration.

\subsection{Woody regeneration performance}

The central parts of the gaps were expected to be the most favourable for the regeneration of moderately shade-tolerant tree species (e.g. maple and spruce) due to a number of factors, such as high irradiance, increased soil depth, the highest topsoil water content (considering the extreme drought event of the summer of 2003), the higher anticipated $\mathrm{N}$ availability (Ritter et al. 2005) and the reduced nutrient uptake by the tree roots (Bormann and Likens 1986). Nevertheless, the competition of ground vegetation hindered the establishment of tree species in the gap centres. Similar results were reported in other studies (e.g. Diaci 2002; Modry et al. 2004; Mountford et al. 2006; Van Couwenberghe et al. 2010). The exception was the growth of already established, dominant beech seedlings. Furthermore, we recorded higher densities of maple and beech small seedling in the low-light conditions within the first year after gap creation, as previously confirmed by Diaci (2002), Mountford et al. (2006) and Roženbergar et al. (2007). The densities of the small fir seedlings and tall beech seedlings were highest along the sun-exposed gap edges (gap position D), whereas there was more small maple seedlings along the gap edges with less sun exposure (gap position A). Furthermore, these less sun-exposed gap edges had less ground vegetation coverage, less direct and total irradiance, higher topsoil moisture and a thicker organic layer than the sunexposed edges (gap position D). Both of these transition positions (gap positions A and D) received more irradiance than the nearly closed canopy (position C) and are likely important for the survival of tall seedlings and saplings. These observations are consistent with previously reported recruitment patterns of canopy gaps in beech forests in England (Mountford et al. 2006) and canopy gaps in mixed broadleaved stands in northern France (Van Couwenberghe et al. 2010). In this study, small maple seedlings were not favoured in the central parts of the gaps, even a few years after the gap creation. This result may be attributed to the maple's shade tolerance during its early developmental stages (seedling bank) and more favourable growing conditions along the gap edges. Because we did not perform any assessment before creating the gaps, it may be assumed that the different seedling banks before the creation of the gaps and the larger survival of the newly established seedlings contributed to this early difference among the gap positions. The latter assumption was supported by larger survival of the maple seedlings under the low-light conditions in subsequent years. In addition, the average distance to seed trees was used as an indicator for differences in seedling banks. The results show that the 
average distance to maple seed trees was greater for the plots in the gap centres, compared to those along the gap edges. Nevertheless, the differences in the distances were small $(4 \mathrm{~m})$. After the creation of the canopy gaps, the proportion of small maple seedlings (based on density) decreased from $78 \%$ in 2001 to $49 \%$ in 2006 . Spruce seedlings were not present in the gaps at the start of the experiment. However, they began to emerge after the creation of the gaps, which indicated that spruce is the least shade tolerant during the early establishment phase.

In addition to vegetation competition, heavy browsing by roe and red deer hindered the recruitment of tree seedlings to higher classes. In particular, fir demonstrated a high establishment potential and an increase in the proportion of small seedlings (from $7 \%$ in 2001 to $23 \%$ in 2006), but the proportion of tall fir seedlings remained low (1-2\%). In firbeech forests and other mixed mountain forests, fir is one of the most susceptible species to browsing (Klopčič et al. 2010). Strong impacts of ungulate browsing on regeneration, with negative consequences for the recruitment of fir into the upper stand canopy (Senn and Suter 2003; Heuze et al. 2005), have been reported in the region during the last two centuries (Roženbergar et al. 2007; Klopčič et al. 2010). In our case, the recruitment was most successful for beech and spruce. Roe deer is usually attracted to sunny patches or areas with dense understories (Heuze et al. 2005) around and within newly created canopy gaps. Despite the improved food supply due to the development of the ground vegetation layer in the gaps and general decrease in the browsing damage for beech, the fir and maple were highly preferred as ungulate food in our study.

\subsection{Variability of ecological factors}

The results of this study demonstrate that the varying distributions of diffuse and direct irradiance (light asymmetry sensu Poulson and Platt 1989) contributed to the variable climate within the gaps (Takenaka 1988). Moreover, our study indicates that the micro-climate differences within and around gaps may affect certain soil features and processes, such as soil moisture, temperature and accelerated decomposition (Muscolo et al. 2010), while other features, such as the relief and depth of mineral horizons, remain stable. The lower soil water contents observed under the closed canopy versus in the central parts of the gaps potentially resulted from the increased soil water extraction by the plant roots and the higher interception of the canopy trees under the closed canopy (Vilhar and Simončič 2012). In addition, the significantly lower soil water content along the sun-exposed gap edges (gap position D) appeared to be affected by the asymmetrical irradiance within the gaps and the south to south-eastern aspect, which contributed to the higher soil evaporation rates along these gap edges. The greater variations in the factors characterising the micro-climates in the medium gap contributed to greater heterogeneity of the micro-sites in that gap. Still, the topsoil water content, ground vegetation coverage and plant composition did not differ between the small and medium gaps, whereas substantial differences occurred between these factors within and around the gaps. This pattern indicates that the partitioning of micro-sites within and around the gaps may be more important than gap size differentiation. Nevertheless, future studies involving additional gaps of various sizes are warranted to provide further support for the conclusions from our study.

\subsection{Application of the conceptual model for distinguishing} micro-sites

In our study, the assignment of gap areas to four gap positions based on direct and diffuse site factors was helpful for assessing the variations in irradiance, ground vegetation and woody regeneration dynamics within and around the gaps. Additionally, other soil features, such as the depth of the organic horizon and the availability of soil moisture, were dependent on their gap positions. The results of this study clearly demonstrate that in the medium gap (i.e. central parts of the gaps, gap position B: $31 \%$ of the sample plots), there were a greater number of plots with smaller survival of woody regeneration. The other gap positions (A, C and D) showed larger seedling survival and were evenly represented (21$24 \%$ of the sample plots). In the small gap, only $7 \%$ of the sample plots were assigned to the central parts of the gaps (gap position B), whereas $35 \%$ were assigned to the sun-exposed gap edges (gap position $\mathrm{D}$ ), and $28 \%$ were assigned to the gap edges with less sun exposure (gap position A). These results indicate that in the small gap, the micro-sites were more suitable for the regeneration of tree species.

Silviculturists should consider the spatial distribution of seed trees, mast years, browsing and forest operations, when developing forest management guidelines. The applied conceptual model using four positions based on diffuse and direct irradiance is easy to comprehend and to apply. For example, ground vegetation competition hindered the establishment of tree species in the gap centres. The overall regeneration success was greater along the gap edges, which suggests that irregular gap shapes of small sizes should be created to provide as many of optimal micro-sites as possible or that the gaps should be expanded accordingly while accounting for the specific micro-relief (e.g. avoiding larger canopy gaps on steep south-facing slopes).

\section{Conclusions}

This study presented a few of the mechanisms that affect regeneration in a mixed forest of silver fir and European beech 
(e.g. the importance of advance regeneration of beech, maple and fir and the overall low survival of woody regeneration in gap centres). Taking into account similar site and stand conditions in selected gaps, the higher densities of maple compared to more shade-tolerant beech and fir were expected within the medium gap and within the sun-exposed microsites (D and B). However, in contrast to our expectations, this study indicated that creating almost circular gaps greater in diameter than the stand height may lead to increased ground vegetation coverage that hinders the regeneration of semishade tolerant species such as maple and spruce.

Acknowledgments The study was part of a Ph.D. study, the 5th EU FP project, Nature-based management of beech in Europe (NAT-MAN QLKCT99-1349), ManFor C. BD project, titled "Managing forests for multiple purposes: carbon, biodiversity and socio-economic wellbeing" (LIFE09ENV/IT/000078), EUFORINNO - »European Forest Research and Innovation« (Reg.Pot No. 315982), and several projects conducted within the Program groups "Forest, forestry and renewable forest resources" and "Forest biology, ecology and technology", financed by the Ministry of Education, Science and Sport of the Republic of Slovenia. In addition, we thank the reviewers for their helpful comments on the manuscript.

Open Access This article is distributed under the terms of the Creative Commons Attribution License which permits any use, distribution, and reproduction in any medium, provided the original author(s) and the source are credited.

\section{References}

Aussenac G (2000) Interactions between forest stands and microclimate: Ecophysiological aspects and consequences for silviculture. Ann For Sci 57:287-301

Bormann FH, GE Likens (1986) Pattern and process in a forested ecosystem. Springer-Verlag, New York

Brandani A, Hartshorn GS, Orians GH (1988) Internal heterogenity of gaps and species richness in Costa Rican tropical wet forest. J Trop Ecol 4:99-119

Carlson DW, Groot A (1997) Microclimate of clear-cut, forest interior, and small openings in trembling aspen forest. Agric For Meteorol 87:313-329

Čater M, Levanič T (2013) Response of Fagus sylvatica L. and Abies alba Mill. in different silvicultural systems of the high Dinaric karst. For Ecol Manag 289:278-288

Čater M, Schmid I, Kazda M (2013) Instantaneous and potential radiation effect on underplanted European beech below Norway spruce canopy. Eur J For Res 132:23-32

Čater M, J Diaci, D Roženbergar (2014) Gap size and position influence variable response of Fagus sylvatica L. and Abies alba Mill. For Ecol Manag 325:128-135

Cudlin P, Kieliszewska-Rokicka B, Rudawska M, Grebenc T, Alberton O, Lehto T, Bakker MR, Børja I, Konôpka B, Leski T, Kraigher H, Kuyper TW (2007) Fine roots and ectomycorrhizas as indicators of environmental change. Plant Biosyst 141:406-425

de Chantal M, Leinonen K, Kuuluvainen T, Cescatti A (2003) Early response of Pinus sylvestris and Picea abies seedlings to an experimental canopy gap in a boreal spruce forest. For Ecol Manag 176:321-336
Diaci J (2002) Regeneration dynamics in a Norway spruce plantation on a silver fir-beech forest site in the Slovenian Alps. For Ecol Manag 161: $27-38$

Ellenberg H, Weber HE, Düll R, Wirth V, Werner W (1992) Zeigerwerte von pflanzen in Mitteleuropa. Scr Geobot 18:1-264

Gray A, Spies T (1996) Gap size, within-gap position and canopy structure effects on conifer seedling establishment. J Ecol 84:635645

Heuze P, Schnitzler A, Klein F (2005) Consequences of increased deer browsing winter on silver fir and spruce regeneration in the Southern Vosges mountains: implications for forest management. Ann For Sci 62: $175-181$

Katzensteiner K (2003) Effects of harvesting on nutrient leaching in a Norway spruce (Picea abies Karst.) ecosystem on a Lithic Leptosol in the Northern Limestone Alps. Plant Soil 250:59-73

Klopcic M, Boncina A (2012) Recruitment of tree species in mixed selection and irregular shelterwood forest stands. Ann For Sci 69:915-925

Klopčič M, Jerina K, Bončina A (2010) Long-term changes of structure and tree species composition in Dinaric uneven-aged forests: are red deer an important factor? Eur J For Res 129:277-288

Kobal M, Kristan S, Grudnik P, Vilhar U (2013) Ponudba in povpraševanja na licitacijah vrednejših lesnih sortimentov $v$ Slovenj Gradcu. Supply and demand at auctions for valuable wood assortments in Slovenj Gradec. GV 71:462-470

Leibundgut H (1982) Europäische Urwälder der Bergstufe. Haupt, Bern

Madsen P (1994) Effects of soil water content, fertilization, light, weed competition and seedbed type on natural regeneration of beech (Fagus sylvatica). For Ecol Manag 72:251-264

Matić S (1983) Utjecaj ekoloških i strukturnih činilaca na prirodno pomlađivanje prebornih šuma jele i bukve u Gorskom kotaru. Glas šum pok 21:223-400

Matthews JD (1999) Silvicultural systems. Clarendon Press, Oxford

Modry M, Hubeny D, Rejšek K (2004) Differential response of naturally regenerated European shade tolerant tree species to soil type and light availability. For Ecol Manag 188:185-195

Morecroft MD, Taylor ME, Oliver HR (1998) Air and soil microclimates of deciduous woodland compared to an open site. Agric For Meteorol 90: 141-155

Mosandl R (1991) Die steuerung von waldökosystemen mit waldbaulichen mitteln-dargestellt am beispiel des bergmischwaldes. 46. Heft, Bayerisches Staatsministerium für Ernährung, Landwirtschaft und Forsten

Mountford EP, Savill PS, Bebber DP (2006) Patterns of regeneration and ground vegetation associated with canopy gaps in a managed beechwood in southern England. Forestry 79:389-408

Muscolo A, Sidari M, Bagnato S, Mallamaci C, Mercurio R (2010) Gap size effects on above- and below-ground processes in a silver fir stand. Eur J For Res 129:355-365

Nagel TA, Svoboda M, Kobal M (2013) Disturbance, life history traits, and dynamics in an old-growth forest landscape of southeastern Europe. Ecol Appl. doi:10.1890/13-0632.1

Nobis M, U Hunziker (2005) Automatic thresholding for hemispherical canopy-photographs based on edge detection. Agric For Meteorol 128:243-250

Ott E, Lüscher F, Frehner M, Brang P (1991) Verjüngungsökologische besonderheiten im gebirgsfichtenwald im vergleich zur bergwaldstufe. Schweiz Z Forstwes 142:879-904

Poulson TL, Platt WJ (1989) Gap light regimes influence canopy tree diversity. Ecology 70:553-555

Proe MF, Griffiths JH, McKay HM (2001) Effect of whole tree harvesting on microclimate during establishment of second rotation forestry. Agric For Meteorol 110:141-154

Puncer I (1980) Dinarski jelovo-bukovi gozdovi na Kočevskem. Razprave 22:161

Regent (2003) WinSCANOPY for hemispherical image analysis. Regent instruments 
Renaud V, Rebetez M (2009) Comparison between open-site and belowcanopy climatic conditions in Switzerland during the exceptionally hot summer of 2003. Agric For Meteorol 149:873-880

Ritter E, Vesterdal L (2006) Gap formation in Danish beech (Fagus sylvatica) forests of low management intensity: soil moisture and nitrate in soil solution. Eur J For Res 125:139-150

Ritter E, Dalsgaard L, Einhorn KS (2005) Light, temperature and soil moisture regimes following gap formation in a semi-natural beechdominated forest in Denmark. For Ecol Manag 206:15-33

Roženbergar D, Mikac S, Anić I, Diaci J (2007) Gap regeneration patterns in relationship to light heterogeneity in two old-growth beech-fir forest reserves in South East Europe. Forestry 80:431-443

Roženbergar D, Kolar U, Čater M, Diaci J (2011) Comparison of four methods for estimating relative solar radiation in managed and oldgrowth silver fir-beech forest. Dendrobiology 65:73-82

Schmidt-Vogt H (1972) Untersuchungen zur Bedeutung des Lichtfaktors bei Femelschlagverjüngung von Tannen-Buchen-Fichten Wäldern im westlichen Hochschwarzwald. Forstwes Cbl 91:238-247

Senn J, Suter W (2003) Ungulate browsing on silver fir (Abies alba) in the Swiss Alps: beliefs in search of supporting data. For Ecol Manag 181:151-164

Stancioiu PT, O'Hara KL (2006) Leaf area and growth efficiency of regeneration in mixed species, multiaged forests of the Romanian Carpathians. For Ecol Manag 222:55-66

StatSoft Inc (2011) STATISTICA (data analysis software system). 10 edn

Takenaka A (1988) An analysis of solar beam penetration through circular gaps in canopies of uniform thickness. Agric For Meteorol 42:307-320
Urbančič M, Simončič P, Čater M (2005) Impacts of gaps on humus forms in dinaric silver fir-beech (Omphalodo-Fagetum) and soil solution quality. Mitt ÖBG 72:179-187

Van Couwenberghe R, Collet C, Lacombe E, Pierrat J-C, Gégouta J-C (2010) Gap partitioning among temperate tree species across a regional soil gradient in windstorm-disturbed forests. For Ecol Manag 260:146-154

Vilhar U (2006) Vodna bilanca dinarskega jelovo-bukovega gozda na Kočevskem rogu. Water balance of a dinaric silver fir-beech forest In Kočevski Rog. PhD, Univerza v Ljubljani

Vilhar U, Simončič P (2012) Water status and drought stress after gap formation in managed and semi-natural silver fir-beech forests. Eur $\mathrm{J}$ For Res 131:1381-1397

Vilhar U, Simončič P, Kajfež-Bogataj L, Katzensteiner K, Diaci J (2006) Mikroklimatske razmere $\mathrm{v}$ vrzelih in sestojih dinarskega jelovo-bukovega gozda. Microclimate conditions in gaps and mature stands of Dinaric silver fir-beech forests. ZbGL 81:21-36

Vilhar U, Starr M, Katzensteiner K, Simončič P, Kajfež-Bogataj L, Diaci J (2010) Modelling drainage fluxes in managed and natural forests in the Dinaric karst: a model comparison study. Eur J For Res 129: 729-740

Walters MB, Lajzerowicz CC, Coates KD (2006) Soil resources and the growth and nutrition of tree seedlings near harvest gap-forest edges in interior cedar-hemlock forests of British Columbia. Can J For Res 36:62-76

Zar JH (1999) Biostatistical analysis. Prentice Hall, Upper Saddle River 